\title{
ORIGINS AND PHILOSOPHY OF TECHNOLOGY
}

$\mathrm{L}^{\mathrm{A}}$ ARGE corporations both in the United States and Britain have recently been giving attention to the more metaphysical aspects of the power they embody or produce, and considering the direction of the steps they intend to take in the second half of the twentieth century. In the United States, General Motors employed Peter Drucker to sketch for them "The Concept of the Corporation". In Britain, from the periphery of an industrial conference, similar heart-searchings are visible. Perhaps the best description for this activity is Adolf Berle's "Matrix Work", which he defined as "tending towards a body of sophisticated thinking whose aim, properly organized, is a concept of a community making for the good life".

Big bites into the edges of this vast and important sphere of thinking have just been made by the Electricity Council. Its chairman, Sir Henry Self, is particularly well qualified to do so, for in the midst of a distinguished career at the Board of Trade, the Post Office, the Foreign Office, the War Office, the Air Ministry and the British Electricity Authority, he has found time to supplement his originally scientific training by separate academic qualifications in mathematics, divinity, classics and philosophy. Having ploughed, harrowed and sown such diverse fields, all in their way fertile, he has now been winnowing the harvest of a life-time. Moreover, as president of the Modern Churchman's Union he is particularly concerned with presenting in contemporary terms a teleology of the modern world. $\mathrm{H}_{\theta}$ sees the universe as a complex of experience in every conceivable form at any possible level. He cites the collect in the "Book of Common Prayer" that prays for the grace not only to "read, mark and learn" but also to "inwardly digest" that which is "written for our learning". His introduction to the eight lectures* which were delivered to an invited audience of members of the senior staff of the Electricity Supply Industry in the autumn of 1956 emphasizes the inward nature of this digestive process.

As an aperitif, he has assembled three well-known figures to present the fruits of their work on the history of science : Prof. H. Dingle, Prof. D. McKie and Dr. P. Dunsheath. Each takes two strands of human

" "The History and Philosophy of Science and Technology". Pp. vi +139 . 98. (Education and Training Department of the
Electricity Council, London, 1958.) thought and development which has fundamental significance for an understanding of our times and which, in Sir Henry Self's view, can be used as "the basis for future development of twentieth century life". Prof. Dingle presents us with Galileo and the beginnings of modern science, Prof. McKie follows on with the Royal Society and the scientific academies, and of course Lavoisier and the beginnings of modern chemistry. Prof. Dingle returns with a lecture on the nineteenth century and the expansion of the physical sciences, and Dr. Dunsheath with two lectures on the engineer and human progress. Sir Henry Self has not only given the introductory and the concluding lecture but has also published a further booklet*, treating in a complementary way twentieth century science and its implications for modern thinking. In this he confines himself to the exact sciences, but promises us further supplements on biology, medicine and psychology.

To the philosopher these two booklets are interesting and significant in that they reveal Sir Henry as a disciple of that great scientific statesman, Viscount Haldane, to whom, as much as any man, we owe the foundation of the Department of Scientific and Industrial Research. For he sees society evolving through community, creative adventure and the pursuit of truth. He is concerned with the bipolar nature of man. As a twentieth century mystic in the tradition of Boehme, William Law and Coleridge (though he does not shelter behind their names) he says "we have got to try and break from the bad habit which has grown over seven centuries whereby we are so proud of our empirical development, of the idea of trial and error, experiment and test, that having developed that we have thrown away the origins, the sources, out of which it sprang". These origins and sources show man, not as a super-computor capable of grinding out thoughts, words and ideas with a brain and a nervous system, but a living em. bodiment of ideas which have enduring eternal value.

Texts are out of fashion. If one were to be put on the front of these two booklets it would be Romans, i, 20: "For the invisible things of him from the creation of the world are clearly seen, being understood by the things that are made".

\section{W. H. G. Armytage}

* Sir Henry Self, "Some Implications of Modern Science". Pp. $\mathrm{ii}+18$. 1s. 6d. (El ectricity Council, London, 1958.)

\section{IONS OF THE TRANSITION ELEMENTS}

\begin{abstract}
A GENERAL discussion organized by the Faraday Society on "Ions of the Transition Elements" was held in Dublin during September 9-11. The main object was to consider the electronic structures and properties of these ions, particularly when included in complexes. A further object was to bring together physicists whose work was concerned with the structures of these ions and theoretical and experimental chemists whose interests lay in the same direction. It was most fortunate that both Prof. L. Pauling (California Institute of Technology)
\end{abstract}

and Prof. J. H. Van Vleck (Harvard University) could be present, for their names are intimately connected with two of the most important theories that have been applied to the electronic structures of these compounds.

Two introductory papers at the beginning of the meeting were given by Dr. J. W. Linnett (University of Oxford) and Prof. M. H. L. Pryce (University of Bristol). The former surveyed the theories and experimental methods that have been employed, while the latter considered, in very general terms, 
the special features of the electronic structures of these ions from the physicist's point of view.

The first session was devoted to four papers which dealt with optical absorption. The first, by Dr. W. P. Doyle and G. Lonergan (University College, Dublin), described some measurements on the transmission of radiation by films of cobaltous and nickelous oxides between 360 and $1,000 \mathrm{~m} \mu$ thick. The first maxima for both were interpreted as exciton transitions. The results were discussed on the basis of crystal field theory. The next two papers both dealt with the absorption spectra of transition metal ions in lattices of $\mathrm{Al}_{2} \mathrm{O}_{3}$. Prof. Pryce and W. A. Runciman (Harwell) studied trivalent vanadium in corundum, while Dr. S. Sugano and Dr. Y. Tanabe (University of Tokyo) considered trivalent chromium in ruby. The former workers succeeded in resolving the fine structure of two absorption bands and then considered theoretically the energylevels for two $d$-electrons in a trigonal field. Sugano and Tanabe reported on the $\mathrm{Cr}^{3+}$ line spectrum in ruby and also discussed its interpretation. Prof. H. Hartmann and H. Müller (University of Frankfort) measured the spectra of the hexa- and heptahydrates of nickel sulphate to compare with calculations that had been made on the $\mathrm{Ni}\left(\mathrm{H}_{2} \mathrm{O}\right)_{6}{ }^{2+}$ ion. The results satisfy the theoretical requirements. A splitting of the main bands, indicating a departure from octahedral symmetry, was observed. The discussion at this session was mainly concerned with the reasons why certain substances were very intensely coloured.

The next five papers dealt with the application of paramagnetic resonance spectroscopy to transition metal ions. Dr. J. Owen (University of Oxford) reviewed the use of electron- and also nuclearresonance to measure electron transfer. He also considered superexchange between pairs of iridium ions in mixed crystals of $\left(\mathrm{NH}_{4}\right)_{2}(\mathrm{Ir}, \mathrm{Pt}) \mathrm{Cl}_{6}$ containing sufficient iridium to ensure the presence of enough pairs of iridium ions which were nearest neighbours, but which had no other iridium neighbours. Dr. W. Hayes (Argonne National Laboratory) had studied ions such as $\mathrm{Cr}^{+}$and $\mathrm{Fe}^{+}$contained in a sodium fluoride lattice and produced there by $\gamma$-rays, X-rays or electrons. The fluorine hyperfine structure was used to measure the amount of electron transfer to the fluorines. Prof. J. E. Wertz, J. H. E. Griffiths and J. W. Orton (University of Oxford) and P. Auzins (University of Minnesota) described experiments with single crystals of magnesium oxide which contain iron group impurities. Because of the high dilution and exact cubic symmetry the lines are very narrow and in some specimens 200 lines were observed. These spectra can be used to study lattice defects.

J. F. Gibson, Dr. D. J. E. Ingram and Dr. D. Schonland (University of Southampton) presented results for electron resonance measurements of ferrihæmoglobin derivatives. A molecular-orbital treatment for these square-bond derivatives was given and the conclusions compared with the results for this and similar copper and cobalt complexes. Dr. J. S. Griffith (University of Cambridge) gave a theoretical treatment of the electronic structures of these complexes, his approach being a crystal field one. He examined his conclusions in relation to the electron resonance and magnetic susceptibility measurements.

The next two papers dealt with magnetic properties. Van Vleck discussed the magnetic anisotropy of crystals and the occurrence of inverted crystalline energy-levels. $\mathrm{He}$ concluded that, while the cubic part of the field is quite stable, the non-cubic part may be very dependent on the nature of the cation. Dr. B. N. Figgis, Dr. J. Lewis, Prof. R. S. Nyholm and R. D. Peacock (University College, London) measured the magnetic susceptibilities of some complexes of osmium, ruthenium, rhenium and iridium over a temperature range. The configurations $d e_{t}{ }^{3}$, $d e_{t}^{4}$ and $d e_{t}^{5}$ were involved. The results were discussed in terms of Kotani's theory.

Dr. C. K. Jorgensen (Technical University of Denmark, Copenhagen) discussed the decrease in repulsion between electrons in the $d$-shell of a complex ion compared with that in a free ion. The effect is due partly to an expansion of the $d$-orbitals because of increased screening and partly to their participation in covalent bonding. Prof. D. P. Craig and E. A. Magnusson (University College, London) also discussed this effect from a theoretical point of view and concluded that the effect could be largely explained without electron transfer into the $3 d$ orbitals.

Dr. J. Chatt, L. A. Duncanson, B. L. Shaw (Imperial Chemical Industries, Welwyn) and L. M. Venanzi (University of Oxford) described measurements using infra-red spectra of the $\mathrm{N}-\mathrm{H}$ vibration frequencies in various amine complexes. They discussed their results in terms of the extent and type of the electron drifts taking place. Dr. R. J. P. Williams (University of Oxford) showed that the stabilities of complexes cannot always be correlated with the ligand field-splitting factor. $\mathrm{He}$ concluded that stabilities should be related only to the groundstate properties and not to the excitation measured by the splitting factor.

Dr. L. E. Orgel (University of Cambridge) discussed the structure of a number of transition metal oxides, considering in particular distortions from a regular arrangement. He also examined the relation of this to the phenomenon of ferroelectricity. N. S. Hush (University of Bristol) presented graphs showing the variation in internuclear separation for the halides, oxides, etc., of the transition metals of the first long period. He also made calculations relating to these distances and contractions in them.

Dr. L. A. K. Staveley and T. Randall (University of Oxford) described measurements they had made of the heats of formation of a large number of complexes involving ethylenediamine tetraacetic acid. Combining their data with measurements of stability constants, they obtained entropy changes. The values were compared with one another and it was found that they fell into several sets. This was discussed. Dr. A. A. Vlcek (Academy of Sciences, Prague) described some work on polarographic halfwave potentials of a series of complexes and found that the potential could be correlated with the position of the ligands in the spectrochemical series. This and other results were then discussed in terms of the mechanism of the electrode process.

Throughout the meeting there was active discussion between the physicists and those chemists whose interests were definitely on the theoretical side or tended that way. But at times it did seem that there is still a great need for a better presentation of the theoretical ideas and nomenclature to the chemists whose activities are more largely experimental.
J. W. LINNETT 